
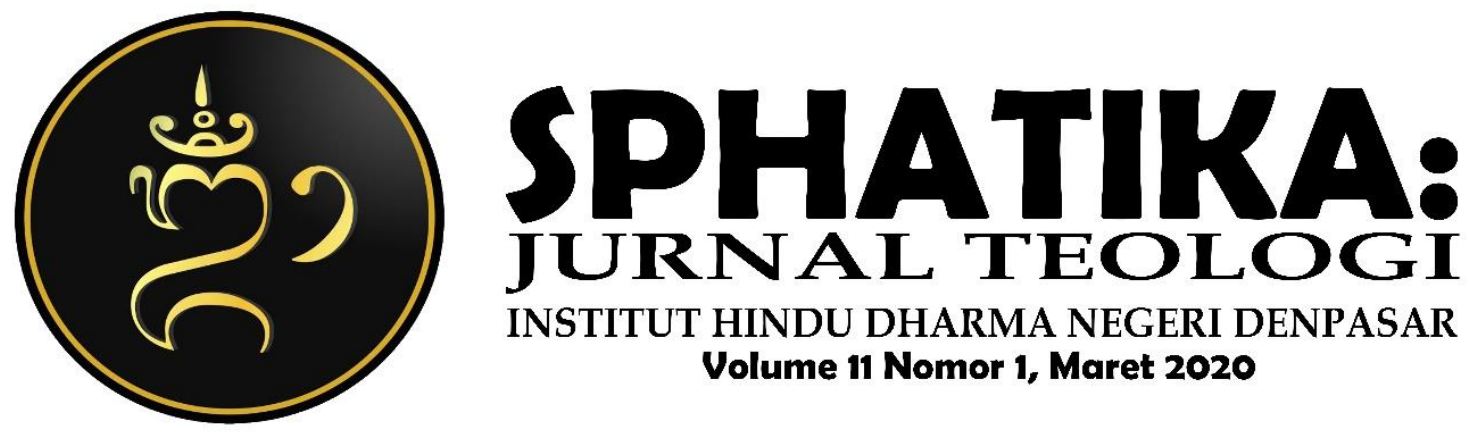

\title{
TEOLOGI INKLUSIF UNTUK MEMBANGUN KERUKUNAN (ANALISIS TEKS TUTUR JATISWARA)
}

\author{
I Komang Suastika Arimbawa \\ Putu Ayu Septiari Dewi
}

Institut Hindu Dharma Negeri Denpasar

\begin{tabular}{|ll|}
\hline Keywords: & ABSTRACT \\
\cline { 2 - 2 } inclusive theology, harmony, Harmony can be interpreted as a living and living \\
condition that reflects an atmosphere of peace, order, peace, \\
prosperity, respect, respect, price respect, tolerance, mutual \\
cooperation in accordance with religious teachings. Harmony \\
that adheres to the teachings of each religion can make every \\
group among fellow human beings who have different beliefs as \\
an open group (inclusive). Regarding this reality, in the text of \\
Tutur Jatiswara there is an inclusive theological concept that \\
can be a "nutrient" to build harmony, so that a plural religious \\
life can live harmoniously, peacefully and help one another in \\
the joys and sorrows. Inclusive is a way of thinking and an \\
open attitude to all differences. Inclusive theology opens the \\
door to apology and recognizes the existence of truth and \\
salvation in other religions. \\
Based on several excerpts in the text of Tutur \\
Jatiswara, that truth is not narrow and not exclusive, because \\
the truth lies in a vast expanse. This means that the truth \\
radiates on each side. Because it radiates on every side, humans \\
must build an inclusive paradigm of thinking so that they can \\
become 'religious people', not just 'feel' religious or do religious \\
activities. By being a religious person, the application of life \\
together will form mutual respect (price-respecting), \\
compassion (love-loving), and fostering (respect) towards \\
adherents of different religions because they have the same \\
rights.
\end{tabular}




\section{PENDAHULUAN}

Pada hakikatnya dalam konteks kemanusiaan setiap agama mengajarkan komitmen kebersamaan dalam hidup dengan keharusan mengesampingkan unsurunsur primordialisme yang menyelimuti kehidupan manusia. Oleh karena itu, setiap agama memiliki konsep yang sama tentang kesetaraan umat manusia untuk mencapai kehidupan yang baik tanpa adanya sekat dalam keberagaman (Nurfitasari, 2014: 3). Namun, dalam perkembangan kehidupan beragama di masyarakat, tidak bisa dipungkiri bahwa gesekan-gesekan dengan latar belakang agama (konflik agama) masih sering terjadi.

Elizabeth K. Nottingham mengatakan bahwa agama memang memiliki potensi ganda, yaitu sebagai unsur pemersatu dan sekaligus berpotensi untuk memecah belah. Agama sebagai keyakinan menyangkut kehidupan bathin seseorang (inner life) yang berhubungan dengan sistem nilai. Sistem nilai yang dianggap paling tinggi adalah nilai-nilai agama yang ajarannya bersumber dari Tuhan. Maka tidak mengherankan apabila agama sering dijadikan "alat pemicu" yang paling potensial untuk melahirkan suatu konflik (Jalaluddin, 2012: 403-404).

Konflik yang berlatar belakang agama sebagai perilaku keagamaan yang menyimpang dapat terjadi karena adanya "pemasungan" nilai-nilai ajaran agama itu sendiri, artinya para penganut agama seakan memaksakan nilai-nilai ajaran agama sebagai "label" untuk membenarkan tindakan yang dilakukannya, padahal yang dilakukan sesungguhnya bertentangan dengan nilai-nilai ajaran agama itu sendiri. Hendaknya sebagai sesama umat manusia harus saling menjaga, berhatihati dan mawas diri untuk bisa menghindari hal-hal yang sensitif berkenaan dengan simbol-simbol agama. Kemudian bagi yang merasa dihina mestinya mampu menahan emosi dan amarah, boleh saja marah atas segala tindakan yang menyudutkan atau menghina simbol agama, tetapi bukan untuk mengabsahkan kekerasan dan intoleransi. Sungguh tidak dibenarkan menyikapi kemunkaran dengan cara-cara yang lebih munkar. Karena, baik penghinaan maupun pembunuhan adalah sebuah ketercelaan (Haerudin, 2015).

Mewujudkan kerukunan dalam menjalani kehidupan beragama merupakan salah satu usaha untuk menciptakan kebaikan hubungan antar sesama manusia 
yang berbeda keyakinan, sehingga setiap golongan antar sesama manusia yang berbeda agama dapat melaksanakan kewajibannya sesuai dengan kepercayaannya masing-masing. Kerukunan yang berpegang kepada ajaran masing-masing agama dapat menjadikan setiap golongan antar sesama manusia yang memiliki keyakinan berbeda sebagai golongan yang terbuka (inklusif). Golongan yang bersifat inklusif akan memudahkan terwujudnya komunikasi atau hubungan yang baik, apabila anggota dari golongan atau antar golongan agama yang berbeda telah melakukan komunikasi atau hubungan yang baik maka bukan tidak mungkin dapat mengembangkan hubungan tersebut ke dalam berbagai bentuk kerjasama dalam menjalani kehidupan, baik bermasyarakat maupun bernegara.

Mengenai realitas yang plural ini, penulis memberikan suatu "tawaran" mengenai konsep ajaran teologi inklusif guna membangun kerukunan yang terdapat di dalam teks Tutur Jatiswara agar kehidupan keagamaan yang plural dapat hidup harmonis, damai dan saling tolong menolong dalam suka maupun duka, karena manusia adalah insan sosial yang tidak dapat berdiri sendiri, saling membutuhkan antara yang satu dengan yang lainnya.

Tutur Jatiswara merupakan salah satu warisan karya sastra keagamaan yang mengandung pembendaharaan pemikiran dan cita-cita yang dapat dijadikan sebagai pedoman di dalam mengarungi bahtera kehidupan di dunia ini. Selain itu, Tutur Jatiswara juga memuat tentang falsafah kehidupan universal yang dapat diaplikasikan pada masyarakat yang plural. Ini menjadi seperti sebuah "obat penawar" ketika melihat fenomena yang terjadi di masyarakat, di mana pada kehidupan masyarakat yang plural, khususnya di Bali masih adanya diskriminasi, seperti masalah 'soroh', 'kasta', maupun kepercayaan.

\section{PEMBAHASAN}

\section{Kerukunan}

Kerukunan sering diartikan sebagai kondisi hidup dan kehidupan yang mencerminkan suasana damai, tertib, tentram, sejahtera, hormat menghormati, harga menghargai, tenggang rasa, gotong royong sesuai dengan ajaran agama dan kepribadian pancasila (Depag RI, 1997: 8 \& 20). Secara umum kerukunan dapat 
diartikan sebagai suatu keadaan di mana tercipta suatu keseimbangan sosial dalam masyarakat atau suatu keadaan / situasi bebas konflik. Bila ditinjau lebih jauh terutama bila dilihat dari kata dasarnya 'rukun', maka kerukunan bukan hanya sebagai suatu situasi atau kondisi semata tetapi kerukunan lebih mencerminkan suatu relasi yang intim antar individu ataupun kelompok dalam suatu tatanan kehidupan bermasyarakat atau beragama (fajriaha.blogspot.com).

Menurut Syaukani (2008: 5), kata kerukunan berasal dari bahasa arab ruknun, kata jamaknya adalah arkan yang berarti asas, dasar atau pondasi (arti generiknya). Dalam bahasa Indonesia arti rukun ialah:

a. Rukun (nominal), berarti: Sesuatu yang harus di penuhi untuk sahnya pekerjaan, seperti tidak sahnya manusia dalam sembahyang yang tidak cukup syarat, dan rukunnya asas, yang berarti dasar atau sendi: semuanya terlaksana dengan baik tidak menyimpang dari rukunnya agama.

b. Rukun (ajektif) berarti: Baik dan damai tidak bertentangan: hendaknya kita hidup rukun dengan tetangga, bersatu hati, sepakat. Merukunkan berarti mendamaikan, menjadikan bersatu hati. Kerukunan berarti perihal hidup rukun, rasa rukun, kesepakatan: kerukunan hidup bersama.

Kerukunan berarti sepakat dalam perbedaan-perbedaan yang ada dan menjadikan perbedaan-perbedaan itu sebagai titik tolak untuk membina kehidupan sosial yang saling pengertian serta menerima dengan ketulusan hati yang penuh keikhlasan. Kerukunan merupakan kondisi dan proses tercipta dan terpeliharannya pola-pola interaksi yang beragam diantara unit-unit yang otonom. Kerukunan mencerminkan hubungan timbal balik yang ditandai oleh sikap saling menerima, saling mempercayai, saling menghormati dan menghargai, serta sikap saling memaknai kebersamaan (Lubis, 2005: 7-8). Oleh karena itu, yang dimaksud dengan kerukunan adalah hidup damai dan tentram dalam menjalani kehidupan sosial, saling toleransi antara masyarakat yang satu dengan masyarakat yang lainnya, baik yang seagama maupun beda agama, kesediaan untuk menerima adanya perbedaan keyakinan dengan orang atau kelompok lain, dan membiarkan orang lain untuk mengamalkan ajaran yang diyakini oleh masing-masing masyarakat, serta kemampuan untuk menerima adanya perbedaan. 


\section{Tutur Jatiswara}

Kata Tutur Jatiswara terdiri dari kata tutur dan jatiswara. Kata tutur dalam Kamus Jawa Kuna-Indonesia berarti ingatan, kenang-kenangan, kesadaran; lubuk jiwa makhluk yang paling dalam, "budi yang dalam" (tempat persatuan dengan Yang Mutlak); tradisi suci, smrti (sebagai lawan śruti), teks berisi doktrin religi, doktrin religi (Zoetmulder dan Robson, 2011: 1306).

Kata jatiswara dalam Kamus Jawa Kuna-Indonesia berasal dari kata jati dan swara. Kata jati yang pertama berarti kelahiran, bentuk eksistensi yang ditentukan oleh kelahiran; derajat, kasta, keluarga, bangsa; status sejati atau asli dari sesuatu; senyatanya, kondisi sebenarnya dari itu; jujur, dapat dipercaya, berkata atau mengatakan kebenaran. Kedua, bunga melati (yasminum grandiflorum). Ketiga, pohon jati. Keempat, rambut terpilih. Kelima, pertapa perempuan (Zoetmulder dan Robson, 2011: 416-417). Dan kata swara berarti bunyi, suara; huruf hidup; nyanyian (Zoetmulder dan Robson, 2011: 1169).

Teks Tutur Jatiswara merupakan sebuah lontar tutur yang pada pokoknya menguraikan tentang nasehat seorang ayah (orang tua) kepada anaknya agar selalu patuh dan bertingkah laku yang baik sesuai dengan petunjuk yang tersurat dan tersirat dalam sastra-sastra agama. Tutur Jatiswara merupakan salah satu jenis lontar tutur yang nampaknya masih relatif muda melihat lontar ini dibuat di Bali dengan mempergunakan bahasa Bali.

\section{Teologi Inklusif}

Ajaran agama diyakini oleh setiap pemeluknya sebagai sumber ketenangan karena ajaran agama memberikan arah serta makna hidup. Namun, tidak dapat dipungkiri bahwa di era postmodern ini terdapat orang yang membenci bahkan mencaci agama karena dianggap sebagai pemicu diskriminasi dan bahkan konflik. Terlepas dari adanya berbagai pendapat dan sikap orang terhadap agama, peranan agama dalam perkembangan peradaban manusia masih tetap menunjukkan eksistensinya dan kebiasaan-kebiasaan masyarakat yang dilahirkannya terus dijaga, bahkan dibela oleh pemeluknya dari generasi ke generasi berikutnya. Bahkan tidak 
sedikit yang membela dengan cara ektrem (kekerasan, mengangkat senjata, bahkan menggunakan alat peledak.

Menurut Effendi (2012), agama seolah-olah menjadi 'senjata' untuk melakukan gerakan-gerakan yang sifatnya memaksakan umat lain agar ikut dan taat pada ajaran agama yang dianutnya. Hal semacam ini didasari dengan dalih semangat 'jihad' atau tegaknya 'kerajaan Tuhan' di muka bumi. Sikap seperti itulah yang merupakan sikap eksklusif dalam beragama. Eksklusif merupakan sikap menutup diri dan menganggap keyakinan individu atau kelompoknya sebagai satu-satunya kebenaran mutlak, sehingga apa yang ada diluar dirinya adalah keyakinan yang keliru, bahkan salah (truth claim radically).

Alvin Plantiga mengungkapkan bahwa " the tenets of one religions are in fact true; any propositions that are incompatible with these tenets are false" atau John Hick yang mengatakan "the exclusivity think that their description of God is the true description and the others are mistaken insofar they differ from it" (Munawar-Rachman, 2000). Penganut pemikiran eksklusif berpandangan bahwa hanya ada satu kebenaran, yaitu kebenaran yang mereka yakini. Pandangan seperti itu dengan sangat jelas menunjukkan kecenderungan yang fanatik, dogmatis, dan otoriter.

Oleh karena itu, di dalam realitasnya di masyarakat, wajah agama ada yang nampak garang, bahkan menakutkan, ada yang nampak ramah sehingga menyejukkan. Dengan keragaman yang ada, masyarakat pemeluk agama harusnya mampu mewujudkan tatanan sosial yang adil dan toleran. Untuk mewujudkan tatanan sosial yang adil dan toleran ketika 'umat' sedang terlelap dalam tidur panjangnya di ranjang eksklusif, maka harus dibangunkan dengan bijak, dengan paradigma berpikir yang terbuka sesuai dengan kondisi masyarakat yang beragam, yaitu teologi inklusif.

Inklusif adalah suatu cara berpikir dan sikap terbuka atas segala perbedaan yang ada. Teologi inklusif membuka kran apologi dan mengakui adanya kebenaran dan keselamatan pada agama lain. Apa pun yang dirumuskan oleh setiap agama masih mungkin terdapat kelemahan-kelemahan bahkan kesalahan. Setiap agama mempunyai cara tersendiri untuk memandang Tuhan, baik dari nama atau penyebutan-Nya, serta cara melaksankan ajaran agamanya. Oleh ka rena itu tidak 
ada satupun agama dapat menjadi polisi atau hakim atas agama yang lainnya. Dengan tidak adanya polisi agama atas agama lainnya, maka setiap agama memiliki kesempatan untuk mensosialisasikan ajaran agamanya dengan rasa aman dan damai (Donder, 2009: 20). Dengan pemahaman, penghayatan, dan penerimaan ajaran teologi inklusif akan menunjukkan pada suatu hakikat adanya perbedaanperbedaan agama yang mengarah pada terwujudnya kerukunan di dalam kehidupan masyarakat. Teks Tutur Jatiswara menguraikan sebagai berikut:

Yan tuah abešik agama, sinah aluh gati baan ngadanin ané madan melah tur lakar něpukin rahayu (suarga) di sakala nișkala, nanghing déning liu gati bacakan agamané, tur mabina-binaan katěrangané sowang-sowang, ngranayang bingung, makeňehin (nampén) kandugi ané tusing patut laksanayang bakat laksanayang (ané pelih kadén beňeh).

Terjemahannya:

Bila hanya ada satu agama, pasti akan mudah untuk menyatakan yang disebut baik serta akan menemui kebahagiaan (sorga) di dunia dan di akhirat, namun karena banyaknya ada agama, serta berbeda-beda penjelasannya masingmasing, menyebabkan kita bingung menerima sehingga yang tidak baik dilakukan itu dilakukan (yang salah dikira benar).

Kutipan teks Tutur Jatiswara tersebut menunjukkan realitas kehidupan manusia selalu dihadapkan pada 'wajah' plural agama, sehingga pemahaman keagamaan dan keyakinannya pun menampakkan wajah yang beragam. Wajah plural yang ditampilkan ini tidak jarang menimbulkan kebingungan teologis, sehingga tidak sedikit pula orang mengambil jalan yang keliru, yang tidak semestinya dilakukan itu dilakukan dan yang salah dikira benar. Begitu juga sebaliknya, yang harusnya dilakukan tidak dilakukan dan yang benar dianggap salah. Ketika ajaran agama berkembang menjadi 'pembedaan' di masyarakat dan bahkan menimbulkan truth claim sehingga dengan mudahnya mendeklarasikan diri sebagai satu-satunya kebenaran mutlak, maka akan sangat rentan menyebabkan terjadinya perpecahan, baik ekstern maupun intern agama yang bersangkutan. Disinilah agama akan kehilangan esensinya sebagai pengendali kekacauan.

Namun, merupakan hal yang tidak dapat dibantah jika kepercayaan merupakan sesuatu yang melekat erat dalam diri manusia, sifatnya sangat pribadi, terselubung dan kadang-kadang diliputi oleh hal-hal yang bernuansa apologi. Kualitas etos seseorang amat ditentukan oleh nilai-nilai kepercayaan yang melekat 
pada dirinya. Orang bahkan rela mempertaruhkan hidupnya demi kepercayaan yang diyakini sebagai kebenaran yang belum tentu benar secara universal, ini adalah wujud pola berpikir yang sempit, fanatik, eksklusif serta penyia-nyiaan makna kehidupan.

Wilson mengatakan bahwa kalau Marx menganggap agama sebagai candu yang memabukkan dan melenakan masih tidak begitu membahayakan, justru yang membahayakan adalah ketika seseorang menggunakan legitimasi agama untuk menghina orang lain, menganiaya orang lain, membunuh orang lain atau berperang demi memperjuangkan kebenaran agama yang diyakini (Hidayat dan Nafis dalam Kuswanjono, 2006: 2). Namun, dibalik itu semua, manusia tidak dapat hidup tanpa 'ajaran' atau sistem penjelasan tentang kehidupan dan alam (baik itu agama atau apapun namanya). Sehingga sangat dibutuhkan pemahaman akan hal tersebut, karena utuhnya suatu pemahaman akan menghasilkan utuhnya sistem kepercayaan, utuhnya sistem kepercayaan akan menghasilkan utuhnya sistem nilai, dan utuhnya sistem nilai akan memberi manusia kejelasan tentang apa yang baik dan buruk, serta menjadi dasar dari seluruh kegiatannya dalam menciptakan peradaban yang lebih baik di dunia ini.

Keanekaragaman inilah yang seharusnya dipahami dan menjadi dasar untuk membuat ajaran agama menjadi lebih bermanfaat dalam kehidupan sehari-hari, karena kebenaran terpancar ke dalam berbagai kebenaran lainnya. Pancaran kebenaran-kebenaran inilah yang menurut Schuon saling berpartisipasi dan bersimbiosis dengan dialektika sejarah, sehingga bentuk dan bahasa keagamaan mengandung muatan nilai budaya yang berbeda dari komunitas lainnya (Kuswanjono, 2006: 4). Jika realitasnya demikian, maka sudah menjadi swadharma (kewajiban) sebagai pemeluk masing-masing ajaran atau kebenaran, sekaligus sebagai umat manusia untuk bersikap inklusif dalam menyikapi keragaman tersebut. Di dalam teks Tutur Jatiswara disebutkan sebagai berikut:

Mula di jimbaré (ditongosé linggah) tongos melahé (Sang Hyang Ayu). Terjemahannya:

Memang di hamparan (tempat yang lapang) tempat kebenaran (Sang Hyang Ayu). 
Kéto karana cěning buatang gati melajahin agama, èda pisan maboya tekén anak lingsir, nanghing pě̀ešang pešan parek mapinunas, déning tusing karowan dija-dija tongos dharmané, awanan paliyunin jalané tongos nunasang tur pę̌pěsang mapinunas. Terjemahannya:

Itu sebabnya anakku usahakan belajar agama, jangan sekali menyangsikan orang tua, namun sering-seringlah menghadap memohon petunjuk, karena tidak tentu dimana letak kebaikan itu, karenanya perbanyak jalannya tempat memohon serta sering-seringlah memohon petunjuk.

Kéto sami dharmané, kadén sig Padandané tongos dharmané, puputné sig Nang Beňehé.

Terjemahannya:

Demikian semua kebajikan itu, dikira pada Pedanda tempat kebajikan itu, akhirnya pada Nang Beneh tempatnya.

Berdasarkan beberapa kutipan teks Tutur Jatiswara tersebut, kebenaran itu tidak sempit dan tidak eksklusif, karena kebenaran itu terletak di hamparan yang luas. Artinya kebenaran tersebut terpancar di setiap sisi. Karena terpancar di setiap sisi, maka manusia harus membangun paradigma berpikir yang inklusif agar dapat 'menjadi' manusia yang beragama, bukan hanya sekedar 'merasa' beragama atau melakukan aktivitas keagamaan. Dengan menjadi manusia yang beragama, maka dalam aplikasinya pada kehidupan bersama akan terbentuk sikap saling asah (hargamenghargai), asih (cinta-mencintai), dan asuh (hormat-menghormati) terhadap pemeluk agama yang berbeda karena memiliki hak yang sama.

Itulah sebabnya sebagai manusia harus berusaha menumbuhkan paradigma berpikir baru serta memperbanyak jalan untuk menemukan kebenaran, karena kebenaran tidak hanya terpancar pada satu jalan saja, peribahasa mengatakan "banyak jalan menuju Roma" dan jika diibaratkan kebenaran itu seperti sinar matahari, maka tidak hanya manusia saja yang mendapatkan pancaran sinarnya, tetapi juga hewan, tumbuhan, serta makhluk hidup lainnya yang ada di alam semesta ini mendapatkan sinarnya. Pola berpikir serta pemahaman seperti itu wajib dikembangkan oleh seluruh umat manusia agar tidak tersesat dalam 'kenampakan' yang plural, karena kebenaran itu sesungguhnya terletak pada substansinya, bukan pada penampilannya. 


\section{PENUTUP}

Teks Tutur Jatiswara mengandung konsep teologi inklusif yang dapat menjadi "nutrisi" untuk membangun kerukunan, sehingga kehidupan keagamaan yang majemuk dapat hidup harmonis, damai dan saling membantu dalam suka dan duka. Dengan pemahaman, apresiasi, dan penerimaan terhadap ajaran-ajaran teologi inklusif akan menunjukkan esensi dari perbedaan agama. Keragaman ini harus dipahami dan menjadi dasar untuk membuat ajaran agama lebih berguna dalam kehidupan sehari-hari, karena kebenaran memancar ke berbagai kebenaran lainnya. Untuk mewujudkan kerukunan, manusia harus membangun paradigma berpikir inklusif sehingga mereka bisa menjadi 'umat beragama', bukan sekedar 'merasa' beragama atau melakukan kegiatan keagamaan. Dengan menjadi orang yang beragama, penerapan hidup bersama akan membentuk sikap saling asah (hargamenghargai), asih (cinta-mencintai), dan asuh (hormat-menghormati) terhadap penganut agama yang berbeda karena mereka memiliki hak yang sama.

\section{DAFTAR PUSTAKA}

Depag RI. 1997. Bingkai Teologi Kerukunan Hidup Umat Beragama di Indonesia. Jakarta: Badan Penelitian dan Pengembangan Agama Proyek Peningkatan Kerukunan Umat Beragama di Indonesia. Diakses melalui digilib.uinsby.ac.id Tanggal 25 Agustus 2015 Pukul 09.54 WITA.

Donder, I Ketut. 2009. Teologi: Memasuki Gerbang Ilmu Pengetahuan Ilmiah tentang Tuhan Paradigma Sanatana Dharma. Surabaya: Paramita.

Effendi, Muhamad Ridwan. 2012. “Teologi Inklusif: Kupas Tuntas Pemikiran Nurcholis Madjid (Cak Nur)". Diakses melalui http://klinikpencerahan.blogspot.co.id Tanggal 16 Pebruari 2016 Pukul 10.55 WITA.

Haerudin, Mamang M. 2015. "Menyikapi Insiden Charlie Hebdo" diakses melalui www.kompasiana.com Tanggal 18 Juli 2015 Pukul 10.00 WITA.

Jalaluddin. 2012. Psikologi Agama, Memahami Perilaku dengan Mengaplikasikan PrinsipPrinsip Psikologi. Jakarta: Rajawali Pers.

Kuswanjono, Arqom. 2006. Ketuhanan dalam Telaah Filsafat Perenial, Refleksi Pluralisme Agama di Indonesia. Yogyakarta: Badan Penerbitan Filsafat UGM.

Lubis, Ridwan. 2005. Cetak Biru Peran Agama. Jakarta: Puslitbang.

Munawar-Rachman, Budhy. 2000. “Mengenbalikan Kerukunan Umat Beragama”. Diakses melalui http://luk.staff.ugm.ac.id Tanggal 16 Pebruari 2016 Pukul 10.17 WITA.

Nurfitasari, Diyah Ayu. 2014. “Teologi Pluralisme dalam Perspektif Pemikiran Gus Dur". (Skripsi). Semarang: Institut Agama Islam Negeri Walisongo Diakses melalui Tanggal 24 Juni 2015 Pukul 01.20 WITA. 
Syaukani, Imam. 2008. Kompilasi Kebijakan dan Peraturan Perundang-Undangan Kerukunan Umat Beragama. Jakarta: Puslitbang.

Zoetmulder, J dan S.O. Robson. 2011. Kamus Jawa Kuna-Indonesia. Terjemahan oleh Darusuprapta dan Sumarti Suprayitna, Jakarta: PT. Gramedia Pustaka Utama. 